\title{
Gram-Negative Diplococcus
}

National Cancer Institute

\section{Source}

National Cancer Institute. Gram-Negative Diplococcus. NCI Thesaurus. Code C122320.

Any bacteria appearing as paired spheres that contains low levels of peptidoglycan in its cell wall and stains pink with the Gram staining technique. 